\title{
TECNOLOGIAS PARA O DESENVOLVIMENTO DE SITUAÇÕES DE APRENDIZAGEM JUNTO A UM ESTUDANTE COM DEFICIÊNCIA INTELECTUAL
}

Ana Virginia Isiano Lima, Klaus Schlünzen Junior, Danielle Aparecida do Nascimento dos Santos, Ana Mayra Samuel da Silva, Denner Dias Barros

Universidade Estadual Paulista - FCT/UNESP, Departamento de Educação, Presidente Prudente, SP. Agência de fomento: Fundação de Amparo à Pesquisa do Estado de São Paulo - FAPESP. E-mail: anaisianolima@gmail.com

\section{RESUMO}

Neste artigo serão apresentados os resultados da pesquisa de iniciação científica "Situações De Aprendizagem Usando Tecnologia Assistiva na Sala de Recursos Multifuncionais para um Estudante com Deficiência Intelectual", processo № 2013 26608-5, vinculada à Fundação de Amparo à Pesquisa do Estado de São Paulo (FAPESP). O objetivo geral foi analisar o desenvolvimento de situações de aprendizagem, utilizando tecnologias, para um estudante com Deficiência Intelectual (DI) visando sua autonomia e aprendizagem significativa. Para o trabalho de campo foram realizados atendimentos educacionais especializados com o estudante na Sala de Recursos Multifuncionais (SRM) do Centro de Promoção para a Inclusão Digital, Escolar e Social (CPIDES) no período de Agosto de 2014 a Julho de 2015. Os resultados demonstraram que os atendimentos contribuíram para o desenvolvimento do estudante em termos da aquisição dos processos de leitura e escrita, autonomia e mobilidade. Além disso, o uso das tecnologias contribuiu para o desenvolvimento de aspectos referentes à sua autonomia e inclusão digital.

Palavras-chave: Atendimento Especializado, Deficiência Intelectual, Tecnologia Assistiva, Recursos.

\section{LEARNING SITUATIONS USING TECHNOLOGY FOR A STUDENT WITH INTELLECUTAL DISABILITIES}

\begin{abstract}
This article deals with the activities of scientific initiation research "Learning Situations Using Assistive Technology Resources at Multifunction Room for a student with Intellectual Disabilities", referring to Case No. 2013 26608-5, the Foundation for Research Support of the State of São Paulo (FAPESP). The research had as main objective to analyze learning situations, using technologies to a student with Intellectual Disability (ID) seeking their autonomy and meaningful learning. Fieldwork was carried out by specialized educational visits with the student at Multifunction Resource Room (SRM) Promotion Center for Digital Inclusion, School and Social (CPIDES). The results showed that the calls contributed to the student's development in terms of acquisition of literacy and search their autonomy. Furthermore, the use of technology has contributed to the development of aspects related to learning and their autonomy.
\end{abstract}

Keywords: Specialized Service, Intellectual Disabilities, Assistive Technology, Resources. 
INTRODUÇÃO

A da pesquisa de iniciação científica intitula "Situações De Aprendizagem Usando Tecnologia Assistiva na Sala de Recursos Multifuncionais para um Estudante com Deficiência Intelectual", processo no 2013 26608-5, da Fundação de Amparo à Pesquisa do Estado de São Paulo (FAPESP), ocorreu na vigência de agosto de 2014 a julho de 2015.

A pesquisa ocorreu no âmbito do Centro de Promoção para a Inclusão Digital, Escolar e Social (CPIDES), da Faculdade de Ciências e Tecnologia (FCT/Unesp). O centro promove a realização de atividades de acompanhamento para estudantes com deficiências, vinculadas ao grupo de pesquisa Ambientes Potencializadores para a Inclusão (API), que desenvolve estudos sobre acessibilidade, estratégias pedagógicas e metodológicas para o uso de recursos tecnológicos com o intuito de incluir pessoas com deficiências.

No CPIDES são realizados atendimentos educacionais especializados junto a Estudantes Público-Alvo da Educação Especial (EPAEE): pessoas com deficiências e transtornos globais do desenvolvimento como autismo, paralisia cerebral, deficiência intelectual, síndrome de down, entre outras. Os atendimentos buscam realizar os mesmos objetivos do Atendimento Educacional Especializado (AEE), que pode ser caracterizado como um serviço de educação especial que "[...] identifica, elabora e organiza recursos pedagógicos e de acessibilidades, que eliminem as barreiras para a plena participação dos alunos, considerando suas necessidades específicas" (SEESP/ MEC, 2008).

De acordo com a política educacional vigente, o AEE deve ser realizado nas Salas de Recursos Multifuncionais (SRM), complementando ou suplementando o ensino regular por um professor especialista, visando a autonomia dos estudantes na escola e fora dela, constituindo oferta obrigatória pelos sistemas de ensino.

Durante a realização dos atendimentos, os pesquisadores e estagiários são orientados a trabalhar com aspectos da autonomia dos estudantes, buscando sua inclusão social, escolar e digital. Para tanto, são utilizados recursos pedagógicos acessíveis e as atividades realizadas são direcionadas de acordo com os interesses dos estudantes, dentro de uma abordagem metodológica considerada Construcionista, Contextualizada e Significativa (CCS) definida por Schlünzen (2000) como,

Um ambiente favorável que desperta o interesse do aluno e o motiva a explorar, a pesquisar, a descrever, a refletir, a depurar as suas ideias. [...] As informações que são significativas para o aluno podem ser transformadas em conhecimento [...] O aluno consegue descobrir a relação com tudo que está aprendendo, a partir de seus interesses individuais dentro do seu contexto. 
Nesse sentido, a pesquisa começou a ser desenvolvida durante atendimento para um estudante diagnosticado com Deficiência Intelectual (DI), objetivando desenvolver situações de aprendizagem, utilizando tecnologias, para o estudante visando sua autonomia e aprendizagem significativa. A partir dos acompanhamentos e de estudos sobre as características e peculiaridades do estudante, traçamos um planejamento para realizar atividades relacionadas ao seu contexto e a seus interesses.

Para a realização dos atendimentos foram utilizados recursos de Tecnologia Assistiva (TA) e Tecnologias Digitais de Informação e comunicação (TDIC), com o intuito de contribuir para sua autonomia e inclusão digital. Desse modo, apresentaremos a forma de organização e execução dos atendimentos realizados e os resultados alcançados durante a pesquisa.

\section{METODOLOGIA}

Para atingir os objetivos do estudo, o desenvolvimento metodológico da pesquisa foi de natureza qualitativa. Segundo Sandín Esteban (2010, p. 127) essa abordagem pode ser caracterizada como uma:

Atividade sistemática orientada à compreensão em profundidade de fenômenos educativos e sociais, à transformação de práticas e cenários socioeducativos, à tomada de decisões e também descobrimento e desenvolvimento de um corpo organizado de conhecimentos.

Conforme Richardson (1999, p.39) é uma metodologia que emprega estudos que podem descrever a complexidade de determinado problema, analisar a interação de certas variáveis, compreender processos dinâmicos sociais, contribuir na mudança de determinado grupo e possibilitar o entendimento de particularidades dos indivíduos. Desse modo, a pesquisa implica o contato direto e prolongado no ambiente a ser investigado.

Inicialmente foi construído um referencial teórico referente às temáticas: Atendimento Educacional Especializado; Deficiência Intelectual; Estratégias de Ensino-Aprendizagem na Sala de Recursos Multifuncionais e Tecnologia Assistiva. A pesquisa bibliográfica sobre esses descritores foi fundamental para analisar e propor estratégias de ensino com os recursos da SRM durante os atendimentos.

O trabalho de campo começou a ser realizado em março de 2014 e foi organizado em atividades semanais, de uma hora. Os atendimentos ocorreram na SRM do CPIDES e mediante a autorização do Comitê de Ética em Pesquisa (CEP), cujo protocolo de aprovação é 106/2009, os 
responsáveis pelo estudante assinaram um termo de autorização para a divulgação de dados e imagens.

Antes de iniciar os atendimentos foram realizadas entrevistas estruturadas com os responsáveis pelo estudante, com o intuito de levantar informações relevantes que nortearam a elaboração do plano de atendimentos, considerando prioritariamente os seus interesses e verificando a necessidade de uso de recursos de acessibilidade. Além de permitir identificar os interesses dos estudantes, as entrevistas permitiram verificar suas potencialidades e dificuldades.

Para a elaboração do plano de atendimentos realizamos um levantamento de recursos de TA, disponíveis na SRM do CPIDES, que poderiam contribuir para a comunicação, a produção e o aprimoramento do nível de aprendizagem do estudante.

Diante desses pressupostos metodológicos foi desenhado o programa de atendimentos, cujos resultados serão descritos a seguir.

\section{RESULTADOS E DISCUSSÃO}

Os atendimentos realizados objetivaram verificar o desenvolvimento do estudante, durante as atividades, em relação ao uso de recursos tecnológicos e da TA. Além da análise de seu desenvolvimento em relação à aprendizagem, buscamos analisar as mudanças biopsicossociais que ocorreram com ele em termos efetivos, sociais e emocionais.

Durante os atendimentos os pesquisadores demonstraram-se atentos aos avanços e dúvidas do estudante. Após cada acompanhamento realizávamos um relatório sistematizado, relatando todas as atividades. Bogdan e Biklen (1994) indicam que os registros devem conter uma parte descritiva e uma parte reflexiva. Na parte descritiva do relatório registramos as maneiras de agir do estudante, as observações realizadas durante os atendimentos, seu envolvimento durante o atendimento e o comportamento do estudante e da pesquisadora diante das atividades realizadas. Em relação à parte reflexiva, relatamos as impressões da pesquisadora, dúvidas, reflexões, sugestões para aprimorar a prática e esclarecimentos necessários para a compreensão da pesquisa.

A partir dos registros e das observações realizadas constatamos que o estudante obteve grande avanço em termos cognitivos e afetivos. No início dos acompanhamentos o estudante não reconhecia todas as letras do alfabeto, não conhecia as famílias silábicas e utilizava a letra de imprensa e a cursiva na mesma palavra. Além disso, se sentia muito inseguro em utilizar o computador durante a realização das atividades. Considerando o desejo do estudante em ser 
alfabetizado, utilizamos situações de aprendizagem que poderiam contribuir com seus desejos e motivação.

As atividades propostas apresentavam as famílias silábicas e estimulavam à escrita. A realização dessas situações de aprendizagem ocorreu com auxílio nos primeiros atendimentos, porém no decorrer dos acompanhamentos o estudante passou a formar palavras simples de forma espontânea. Para a formação de palavras foram confeccionadas letras móveis ampliadas para que o estudante conseguisse visualizá-las sem dificuldade e, para a realização das atividades no computador, adquirimos um teclado ampliado para estudantes com baixa visão com apoio institucional da FAPESP.

Durante o processo percebemos que o uso da tecnologia e de outros recursos foi essencial para a realização das situações de aprendizagem, pois o estudante se sentia mais motivado para realizar as atividades, auxiliando, assim, em seu desenvolvimento.

Diante do exposto percebemos que o estudante obteve avanços significativos em relação a sua alfabetização e autonomia, pois até o presente momento conhece quase todas as famílias silábicas, constrói palavras simples sem auxílio e consegue pensar em cada sílaba da palavra de acordo com seu ritmo e tempo.

Durante a realização da pesquisa percebemos que a construção de práticas usando tecnologias, que valorizem as especificidades dos estudantes com DI, valorizando suas habilidades e potencialidades, auxilia o desenvolvimento de sua autonomia e aprendizagem significativa.

\section{DISCUSSÃO}

A condição da DI não pode nunca predeterminar qual será o limite de desenvolvimento do indivíduo. Desse modo, os atendimentos educacionais voltados a esses estudantes devem privilegiar o desenvolvimento e a superação daquilo que lhe é limitado, que permita a saída de uma posição passiva e automatizada diante da aprendizagem para o acesso e apropriação ativa do próprio saber, ou seja, desenvolvimento da autonomia intelectual.

De acordo com Falconi e Silva (2010) o atendimento para estudantes com DI não deve voltar-se apenas para o nivelamento cognitivo, centradas nas limitações decorrentes da deficiência, devendo ser aproveitadas as potencialidades que o estudante dispõe, pois para que ocorra a aprendizagem significativa, as estratégias de ensino precisam estar articuladas ao interesse do estudante e ao que ele já sabe.

Como o estudante tinha grande desejo em ser alfabetizado, desenvolvemos atividades que iam ao encontro de seus desejos, utilizando recursos e temas diversos. Falconi e Silva (2010) 
afirmam que o processo de alfabetização de estudantes com DI é semelhante a dos estudantes que não possuem deficiência, a diferenciação relaciona-se ao ritmo de aprendizagem, pois os estudantes com DI requerem um período mais longo para a aquisição da língua escrita.

Nesse sentido, as estratégias de ensino objetivavam proporcionar ao estudante a contextualização da escrita com o seu cotidiano, para que ele tivesse interesse em construir seu conhecimento e produzisse sentido para a linguagem.

Diante dos resultados expostos, percebemos que o uso das tecnologias favoreceu a construção do conhecimento do estudante, motivando-o a realizar as atividades no computador. Além disso, o uso de recursos de TDIC e TA possibilitou a realização de pesquisas, busca por vídeos de seu interesse, aprendizagem sobre seu uso e outros conhecimentos presentes durante os atendimentos.

\section{CONCLUSÃO}

Diante do exposto observamos que mediante a proposta de situações de aprendizagem usando TDIC o estudante obteve avanços significativos em relação a sua alfabetização. Até o presente momento já conhece quase todas as famílias silábicas, constrói palavras simples sem auxílio e consegue pensar em cada silaba da palavra de acordo com seu ritmo e tempo.

A partir da pesquisa percebemos que a construção de práticas usando tecnologias que valorizem as especificidades dos estudantes com DI, valorizando suas habilidades e potencialidades, auxilia o desenvolvimento de sua autonomia e aprendizagem significativa.

\section{REFERÊNCIAS}

BOGDAN, Roberto C. \& BIKLEN, Sari Knopp. Investigação qualitativa em educação: uma introdução à teoria dos métodos. Porto: Porto Editora, 1994.

BRASIL: Ministério da Educação. Secretaria da Educação Especial. Atendimento Educacional Especializado: Deficiência Física. Brasília: MEC/SEESP, 2008.

FALCONI, E. R. M; SILVA, N. A. S. Estratégias de Trabalho para Alunos com Deficiência Intelectual. 2010.

RICHARDSON, Roberto J. et al. Pesquisa social: métodos e técnicas. ed. rev. e amp. São Paulo: Atlas, 1999.

SANDÍN ESTEBAN, M.P. Pesquisa qualitativa em educação: fundamentos e tradições. Porto Alegre: AMGH, 2010.

SCHULÜZEN, E. T. M. Mudanças nas Práticas Pedagógicas do Professor: Criando um Ambiente Construcionista, Contextualizado e Significativo para Crianças com Necessidades Especiais Físicas. 
2000. 212 f. Dissertação (Doutorado em Educação) - Pontifícia Universidade Católica, São Paulo, 2000. 